\title{
Anatomía radiológica de la base de cráneo y los nervios craneales parte 1: Generalidades y base de cráneo
}

\author{
Andrés Miranda-Merchak ${ }^{1,2}$, Cristina Kuschel ${ }^{3}$, Maximiliano Miranda ${ }^{2,4}$ Anibal Fuentes ${ }^{2,4}$.
}

1. Radiólogo, Servicio Neurorradiología Hospital Barros Luco Trudeau. Santiago - Chile.

2. Servicio Radiología Clínica Dávila. Santiago - Chile.

3. Interna Medicina, Universidad de Los Andes. Santiago - Chile.

4. Residente Radiología, Universidad Mayor. Santiago - Chile.

\section{Skull base and cranial nerves radiologic anatomy part 1: Basics and skull base}

\section{Resumen:}

La anatomía de la base del cráneo es compleja. Numerosas estructuras neurovasculares vitales pasan a través de múltiples canales y formámenes de la base del cráneo. Con el avance de la tomografía computarizada (TC) y la resonancia magnética (RM) es posible la localización cada vez más precisa de lesiones y la evaluación de su relación con las estructuras neurovasculares adyacentes. El trayecto de los nervios craneales sigue un recorrido conocido y se transmiten a la cara y cuello a través de los forámenes de base de cráneo. La TC y la RM son complementarias entre sí y, a menudo, se usan en conjunto para demostrar la extensión completa de la enfermedad. La primera parte de esta revisión se centra en generalidades del estudio radiológico y anatomía de base de cráneo.

Palabras claves: Tomografía computada, resonancia magnética, base de cráneo, nervios craneales.

\section{Abstract:}

The skull base anatomy is complex. Many vital neurovascular structures course through the skull base canals and foramina. With the routine use of CT and MRI, the localization of lesions has become more precise as well as their relationship with adjacent neurovascular structures. There is a known anatomical course of the cranial nerves and their skull base $s$ they course through the foramina towards the head and neck. CT and MRI are complimentary modalities and are often used together to map the full extent of disease. The first part of this review article series focus on the radiologic approach to disease and the skull base anatomy.

Key words: Computed tomography, magnetic resonance imaging, skull base, cranial nerves.

Miranda-Merchak A, et al. Anatomía radiológica de la base de cráneo y los nervios craneales parte 1: Generalidades y base de cráneo. Rev Chil Radiol 2018; 24(3): 105-111.

Correspondencia: Andrés Miranda / andresrobertomiranda@gmail.com

Trabajo enviado el 08 de septiembre de 2018. Aceptado para publicación el 29 de octubre de 2018.

\section{Introducción}

La anatomía de la base del cráneo es compleja. Numerosas estructuras neurovasculares vitales pasan a través de múltiples canales y forámenes ubicados en la base del cráneo. Es necesario tener una aproximación sistemática a la anatomía de la base de cráneo y conocer qué técnica de imagen se debe utilizar para poder optimizar su análisis y eva- luar los distintos procesos que pueden afectarla. La base del cráneo forma el piso de la cavidad craneal que separa el cerebro de las estructuras faciales y el cuello suprahioideo. La anatomía de la base del cráneo es compleja y no está directamente accesible para la evaluación clínica. La base del cráneo está compuesta por cinco huesos: frontal, etmoides, esfenoides, temporales y occipital. Se pueden identificar 
tres regiones naturalmente contorneadas cuando la base del cráneo se observa desde superior, las fosas craneales anterior, media y posterior. Existen numerosos forámenes y canales en la base del cráneo, que transmiten estructuras neurovasculares vitales.

El objetivo de este artículo es graficar de manera esquemática la anatomía en TC y RM de la base de cráneo y los nervios craneales.

\section{Modalidades, técnicas de imagen y consideraciones generales}

La TC y la RM son complementarias entre sí y, a menudo, se usan en conjunto para el diagnóstico de enfermedades de la base del cráneo ${ }^{(1)}$. El rol de las imágenes es detectar la ubicación y extensión de la masa, diferenciar los tumores benignos de los malignos, determinar la resecabilidad, la invasión del parénquima meníngeo o cerebral, la invasión de la órbita, el seno cavernoso o las estructuras vasculares y la diseminación perineural ${ }^{(2)}$.

La mejor modalidad de imagen para cualquier neuropatía aislada o múltiple en general es la RM. Si una lesión es primariamente ósea, como en la base del cráneo, senos paranasales o mandíbula, la TC está recomendada para proveer una información complementaria de la anatomía del hueso y su relación con la lesión ${ }^{(3)}$.

\section{Tomografía computada}

Las imágenes se obtienen desde C2 hasta el ápex craneal. El estudio axial se realiza en el plano de la línea base de Reid, que es la línea trazada desde el margen inferior de la órbita (orbitale point) hasta el punto medio del meato auditivo externo (auriculare point) ${ }^{(4)}$. Con el advenimiento de las TC multicorte, es posible una adquisición volumétrica del cráneo y realizar una reconstrucción multiplanar. Las imágenes se evalúan con algoritmo óseo y de partes blandas. La evaluación postcontraste se puede realizar especialmente cuando se sospecha una lesión vascular o vascularizada(5)

La base del cráneo se evalúa mejor en los planos axial y coronal. Para una mejor visualización, se utiliza un algoritmo de reconstrucción ósea con ventana amplia (ancho: 4,000 nivel: 800). En la evaluación de las partes blandas es recomendable medio de contraste yodado endovenoso.

La TC es la modalidad de elección para definir la anatomía ósea de la base del cráneo y para representar los márgenes corticales delgados de los forámenes neurovasculares de la base de cráneo. La TC es más sensible para detectar la anatomía ósea, el patrón de destrucción ósea, la reacción perióstica, la esclerosis, la osificación, la matriz y la calcificación(6), para la evaluación de fracturas de la base de cráneo y para detectar fístulas de LCR, especialmente tras la administración de contraste intratecal (cisterno-TAC).

\section{Resonancia magnética}

Las imágenes de la base de cráneo se obtienen con una antena de cerebro estándar. Se utilizan los planos sagital, axial y coronal y ponderaciones en T1 sin y con saturación grasa espectral, pre y postcontraste, T2, T2* o imagen ponderada por susceptibilidad (SWI), recuperación de inversión tau corta (STIR), imagen ponderada en difusión (DWI) y adquisiciones volumétricas como gradiente spoiled (SGPR) y una imagen cisternográfica CISS o FIESTA por sus nombres comerciales en inglés. Primero se obtiene una imagen sagital media, que sirve como aproximación inicial. Las imágenes axiales se obtienen desde la cisterna supraselar hasta la nasofaringe. Luego se obtienen imágenes coronales desde la cara anterior del seno esfenoidal hasta el foramen magno(4).

La RM tiene una ventaja sobre la TC para describir la extensión intracraneal (invasión dural, leptomeníngea y del parénquima cerebral), la diseminación perineural y perivascular y compromiso de la médula ósea. Las imágenes axiales y coronales que utilizan imágenes de spin eco rápido ponderadas en $\mathrm{T} 1$ y $\mathrm{T} 2$ deben obtenerse con imágenes postcontraste con supresión grasa usando un campo de visión más pequeño con un grosor de corte de $3 \mathrm{~mm}$. Se obtienen imágenes adicionales en STIR. Las imágenes adquiridas con STIR tienen mejor supresión de grasa, pero tardan más tiempo y son más susceptibles a los artefactos de flujo pulsátil. Las imágenes de gradiente de eco T2 pueden ser útiles para demostrar sustancias paramagnéticas, como calcificaciones, productos de degradación de la sangre o melanina dentro de una lesión ${ }^{(5)}$. Las imágenes de difusión son útiles para caracterización de tumores malignos y benignos ${ }^{(7)}$.

La RM tiene una ventaja sobre la TC en la caracterización de tejidos blandos. En general, las lesiones inflamatorias tienen un alto contenido de agua y una alta intensidad de señal T2W. Los tumores benignos y de bajo grado de glándulas salivales menores, schwannoma, hemangioma y meningioma tienen una señal de T2 alta. Las neoplasias malignas son celulares y tienen intensidad de señal intermedia en imágenes T2. Los valores del coeficiente de difusión aparente (ADC) dentro de las lesiones malignas están disminuidos en comparación con el tejido no maligno. En $1.5 \mathrm{~T}$, se sugiere un valor ADC de $1.22 \times 10 \mathrm{~mm} / \mathrm{s}$ $y$ en $3 T 1.3 \times 10 \mathrm{~mm} / \mathrm{s}$ como posible umbral para distinguir las lesiones benignas de las malignas ${ }^{(7)}$.

En la base del cráneo se pueden identificar tres regiones naturalmente contorneadas cuando se observa desde superior, las fosas craneales anterior, media y posterior.

\section{Fosa craneal anterior}

La base anterior del cráneo forma la parte inferior del cráneo anterior, separando la fosa craneal anterior de los senos paranasales y las órbitas (Figura 1). 


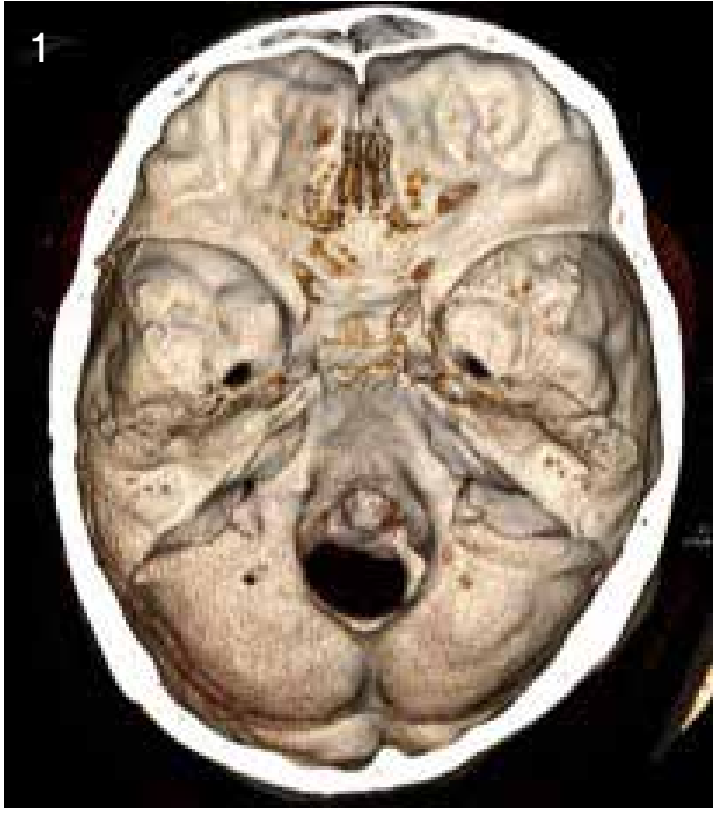

Figura 1: Reconstrucción volumétrica observando desde superior la base de cráneo de una tomografía computada, identificando la fosa craneal anterior, media y posterior.

El borde anterior está formado por la pared posterior del seno frontal y el borde posterior está formado por el ala menor del hueso esfenoides y los procesos clinoideos anteriores. El piso está formado por el techo de la cavidad nasal y los senos etmoidales medialmente. La pared lateral está formada por placas orbitales del hueso frontal, que contribuyen a la mayor superficie de la fosa craneal anterior ${ }^{(6)}$. El sitio donde la arteria etmoidal anterior ingresa a la fosa craneal anterior (laminilla lateral de la lámina cribosa) es el sitio de lesiones óseas comunes y fístulas del líquido cefalorraquídeo (LCR) ${ }^{(6)}$.

La lámina cribosa del hueso etmoides tiene múltiples perforaciones pequeñas que transmiten los nervios olfatorios desde la mucosa nasal hasta el bulbo olfatorio.

\section{Fosa craneal media}

La base craneal media constituye el piso de la fosa craneal media. El hueso esfenoides es el centro de la base del cráneo. Esta estructura anatómicamente compleja contiene forámenes vitales, por el cual transcurren importantes estructuras neurovasculares; constituye el piso de la fosa craneal media; $y$ contiene la hipófisis dentro de la silla turca, así como también los senos cavernosos. Este hueso y sus orificios están involucrados en procesos patológicos primarios de los huesos, enfermedades extracraneales con extensión intracraneana y enfermedades intracraneales que se extienden a través de la base del cráneo.

El borde anterior está formado por el tubérculo selar, los procesos clinoideos anteriores, el margen posterior de las alas menores del esfenoides y el borde anterior y superior de las alas mayores del esfenoides. El borde posterior está formado por los bordes superiores de la parte petrosa del hueso temporal y el dorso selar del esfenoides ${ }^{(1)}$. La parte central de la fosa craneal media está formada por el cuerpo del esfenoides.

Tres importantes forámenes se encuentran dentro del ala mayor: redondo, oval y espinoso, situados desde anteromedial a posterolateral, respectivamente ${ }^{(4)}$. El foramen redondo se encuentra debajo de la fisura orbitaria superior. La mitad medial del ala mayor forma el borde anterior del foramen rasgado y contiene el canal vidiano en la base de las placas pterigoideas.

Canal óptico: El canal óptico está formado por el ala menor del esfenoides (Figura 2) y por el transcurren el nervio óptico (NC II) y la arteria oftálmica ${ }^{(8)}$.

Fisura orbitaria superior: La fisura orbitaria superior está delimitada medialmente por el cuerpo del esfenoides, hacia superior por el ala menor, hacia inferior por el ala mayor y hacia lateral por el hueso frontal a medida que las alas mayor y menor convergen (Figura 2). A través de esta fisura transcurren los nervios oculomotor, troclear y abducens; la primera división del nervio trigémino, la rama orbitaria de la arteria meníngea media, fibras simpáticas del plexo carotideo interno, ramas meníngeas recurrentes de la arteria lagrimal y venas oftálmicas ${ }^{(9)}$.

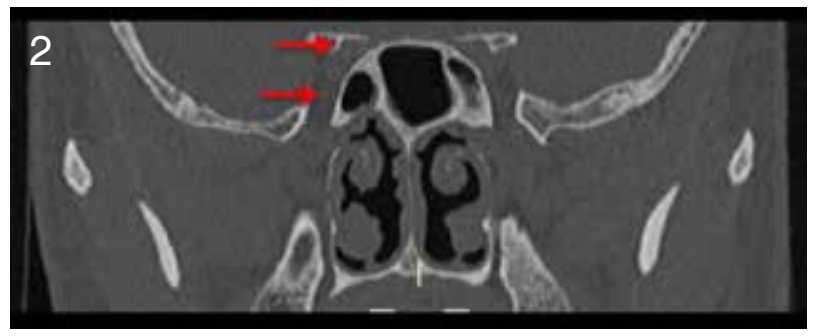

Figura 2: Corte coronal de TC en ventana ósea donde se visualizan el canal óptico (flecha superior) y la fisura orbitaria superior (flecha inferior).

Foramen redondo: Constituye un canal de longitud variable en la base del ala esfenoidal mayor, está situado por inferior y lateral a la fisura orbital superior. El canal comunica la fosa craneal media con la fosa pterigopalatina. Por éste transcurren la rama maxilar del trigémino (V2), la arteria del foramen redondo y venas emisarias ${ }^{(10,11)}$. Este foramen se visualiza mejor mediante un corte coronal y axial en TC (Figura 3).

Foramen oval: Se ubica en el aspecto medial del cuerpo del esfenoides. Por este foramen transcurren la rama mandibular del trigémino (V3), venas emisarias y la arteria meníngea accesoria desde la fosa craneal media a la fosa infratemporal (o espacio masticatorio infrazigomático). Hacia craneal, el foramen oval está 

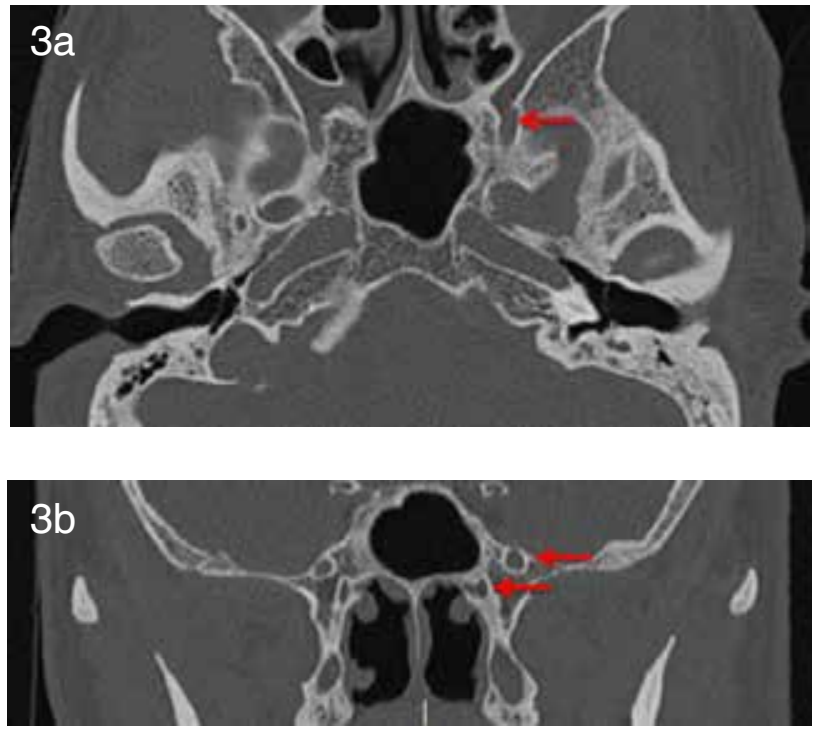

Figura 3: Corte axial (a) y coronal (b) del foramen redondo mayor izquierdo. Se demuestra además el canal vidiano (flecha inferior en $b$ ).

situado posterior y lateral respecto a la cara posterior del foramen redondo; en su porción extracraneal, se encuentra en la base de la placa pterigoidea lateral. El tamaño normal de este foramen varía considerablemente $^{(10)}$. Se puede visualizar en TC con cortes axiales y coronales, mientras que las lesiones de tejidos blandos que lo atraviesan se ven mejor en RM con corte coronal, especialmente posterior a la administración de gadolinio con saturación grasa (Figuras 4 y 5 ).

Seno cavernoso: El seno cavernoso está situado a cada lado del cuerpo del esfenoides y se extienden por anterior desde la fisura orbitaria superior al ápex petroso por posterior. La arteria carótida interna recorre el seno, rodeada por su plexo simpático, mientras que el nervio abducens (NC VI) se encuentra inferior y lateral a la arteria. De superior a inferior, los nervios oculomotor, troclear y las divisiones oftálmica (V1) y maxilar (V2) del nervio trigémino están contenidas dentro de vainas fibrosas que las mantienen separadas dentro de la pared lateral del seno ${ }^{(9,12)}$ (Figura 6). El endotelio separa estas estructuras de la sangre

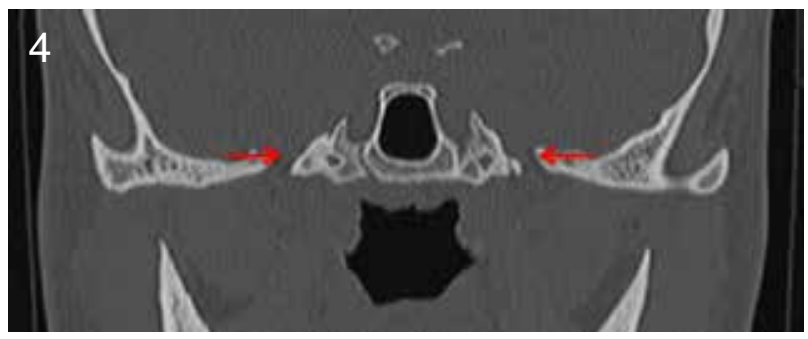

Figura 4: Corte coronal de ambos forámenes ovales (flechas rojas).

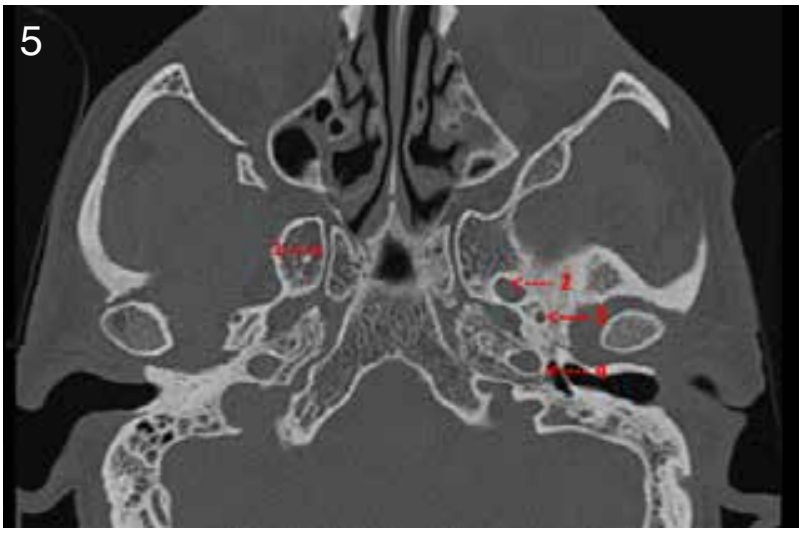

Figura 5: Corte axial de tomografía computada en base de cráneo, en orden descendente se indica el canal vidiano(1), foramen oval(2), foramen espinoso(3) y canal carotídeo(4).

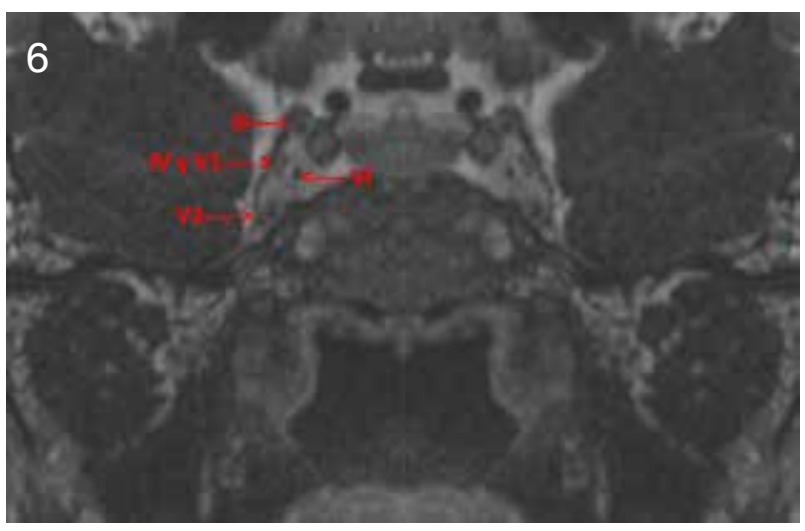

Figura 6: Corte coronal de RM secuencia FIESTA con gadolinio, centrada en seno cavernoso demuestra a izquierda, de craneal a caudal NC III, IV, V1, IV y V2. A derecha su representación en espejo sin indicadores.

venosa contenida en el seno(9). La hipófisis y el seno esfenoidal se ubican mediales al seno cavernoso. El cavum de Meckel, que contiene el ganglio trigémino, está situado posterior e inferior al seno cavernoso ${ }^{(13)}$. El seno cavernoso puede evaluarse con cortes coronales o axiales de TC o RM.

Foramen espinoso: Se encuentra en la cara posteromedial del ala mayor del esfenoides, justo posterolateral al foramen oval por la cara inferior de la base del cráneo y lateral a la tuba faringotimpánica de forma exocraneal. A través de este agujero pasa la arteria y vena meníngea media, rama de la arteria maxilar y la rama recurrente del nervio mandibular ${ }^{(9)}$. Este foramen se visualiza mejor con un corte axial de TCF (Figura 5).

Foramen rasgado o lacerum: La cara caudal del foramen rasgado no es en realidad un foramen, ya que está cubierto por fibrocartílago. Está ubicado en la base de la lámina pterigoidea medial. La arteria carótida no transcurre a través del canal sino que descansa por la cara endocraneal del fibrocartílago, 
formando su piso(11). Una rama meníngea inconstante de la arteria faríngea ascendente y el nervio del conducto pterigoideo perforan el cartílago y son las únicas estructuras que transcurren por el foramen ${ }^{(10)}$. El foramen rasgado y el canal carotideo se pueden visualizar en cortes axial y coronal de TC o RM (Figura 7).

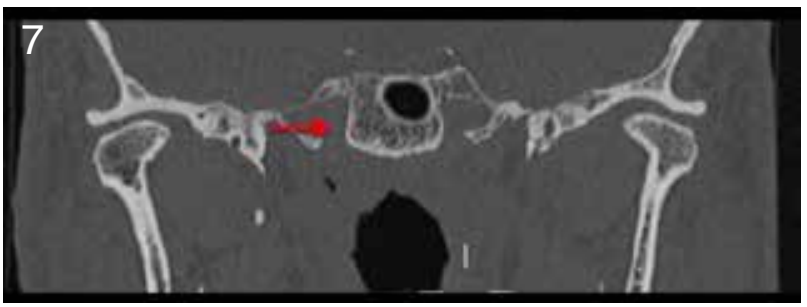

Figura 7: Corte coronal de tomografía computada en ventana ósea en el foramen lacerum.

Canal vidiano o pterigoideo: El canal está situado en la base de las láminas pterigoideas bajo el foramen redondo en el cuerpo del esfenoides. Conecta la fosa pterigopalatina al foramen rasgado y por él transcurren la arteria y el nervio vidiano ${ }^{(10,11)}$. El nervio vidiano (o del canal pterigoideo) es la continuación del nervio petroso superficial mayor (rama del facial desde el ganglio geniculado) después de su unión con el nervio petroso profundo, de origen simpático. La arteria vidiana, rama de la porción terminal de la arteria maxilar interna, surge en la fosa pterigopalatina y pasa a través del foramen rasgado por posterior al nervio del canal pterigoideo. Debido a su proximidad al foramen rasgado, este vaso a menudo proporciona una colateral a la arteria carótida interna ${ }^{(14)}$. Este canal se visualiza mejor en cortes axiales y coronales de TC (Figuras 3 y 5 ).

\section{Fosa craneal posterior}

El margen anterior de la base posterior del cráneo está formado por la superficie posterior del clivus. La porción lateral está formada por la superficie posterior del hueso temporal petroso superior y la parte condilar del hueso occipital por la parte inferior. El hueso temporal mastoideo y el hueso occipital escamoso forman la porción posterior ${ }^{(15)}$. El foramen magno está formado completamente dentro del hueso occipital (Figura 1).

Las estructuras importantes que transmiten a través del foramen magno son el bulbo raquídeo, las arterias vertebrales, las arterias espinales anteriores / posteriores y el nervio espinal o accesorio.

El clivus es la parte de la base del cráneo que está situada entre el dorso selar y el basion del foramen magno. Incluye al cuerpo del esfenoides (basi- esfenoides) y la porción basilar del hueso occipital (basi-occipucio) $^{(16)}$. La fisura petro-occipital forma el margen lateral anterior del clivus, mientras que la sincondrosis entre la porción basilar del hueso occipital y exoccipital forma los márgenes laterales posteriores ${ }^{(13)}$. Hacia inferior el clivus constituye la pared posterior de la nasofaringe.

Conducto auditivo interno: El conducto auditivo interno (CAl) es un canal óseo dentro de la porción petrosa del hueso temporal que transmite los nervios y los vasos desde la fosa craneal posterior al aparato auditivo y vestibular. La apertura del CAI, el poro acústico, se encuentra dentro de la cavidad craneanana, cerca de la superficie posterior del hueso temporal. Los márgenes de la abertura son lisos y redondeados, y el canal es corto $(1 \mathrm{~cm})$, se extiende lateralmente al hueso. El canal se estrecha formando el fundus, que corresponde al límite lateral, donde el canal se divide en tres aberturas distintas, una de las cuales es el canal del facial. El contenido del CAI incluye: nervio facial, nervio vestibulococlear, ganglio vestibular, arteria laberíntica ${ }^{(17)}$ (Figura 8).

Foramen yugular: El foramen yugular se ve en el extremo posterior de la sutura petro-occipital. Anteriormente, la espina caroticoyugular separa el foramen yugular de la abertura carotídea inferior. A lo largo de la cara medial, una barra ósea llamada tubérculo yugular separa el foramen yugular del conducto hipogloso, que transmite el nervio hipogloso. El septum fibroso u óseo divide el foramen yugular en pars nervosa anteromedial y pars vascularis posterolateral. La pars nervosa es más pequeña y más consistente en tamaño, y transmite el noveno (IX) nervio craneal (nervio glosofaríngeo) con su rama

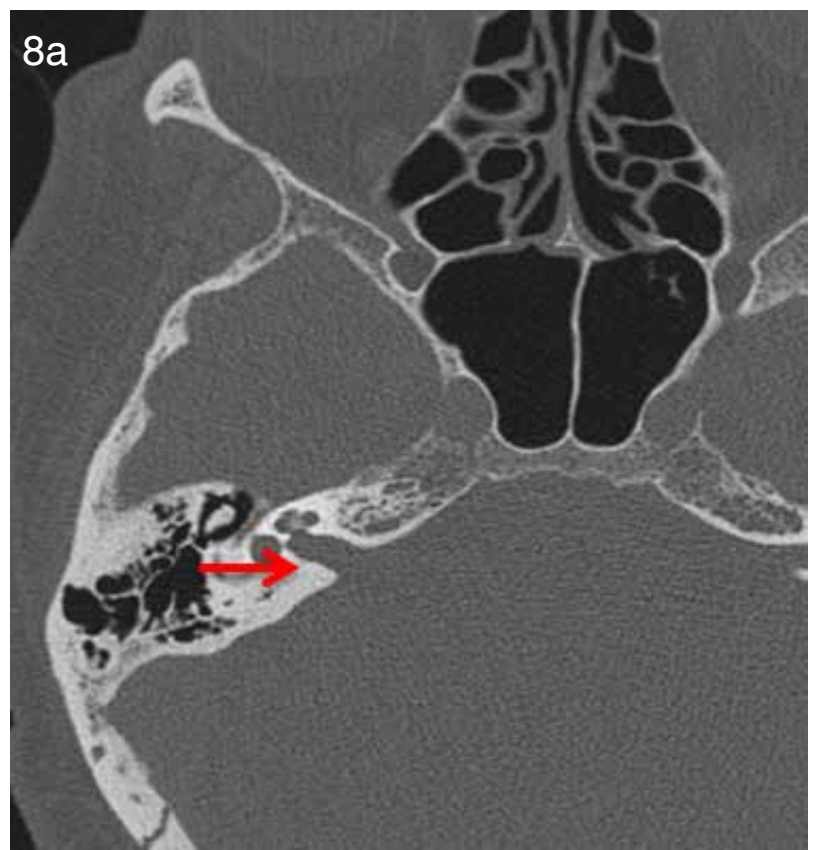



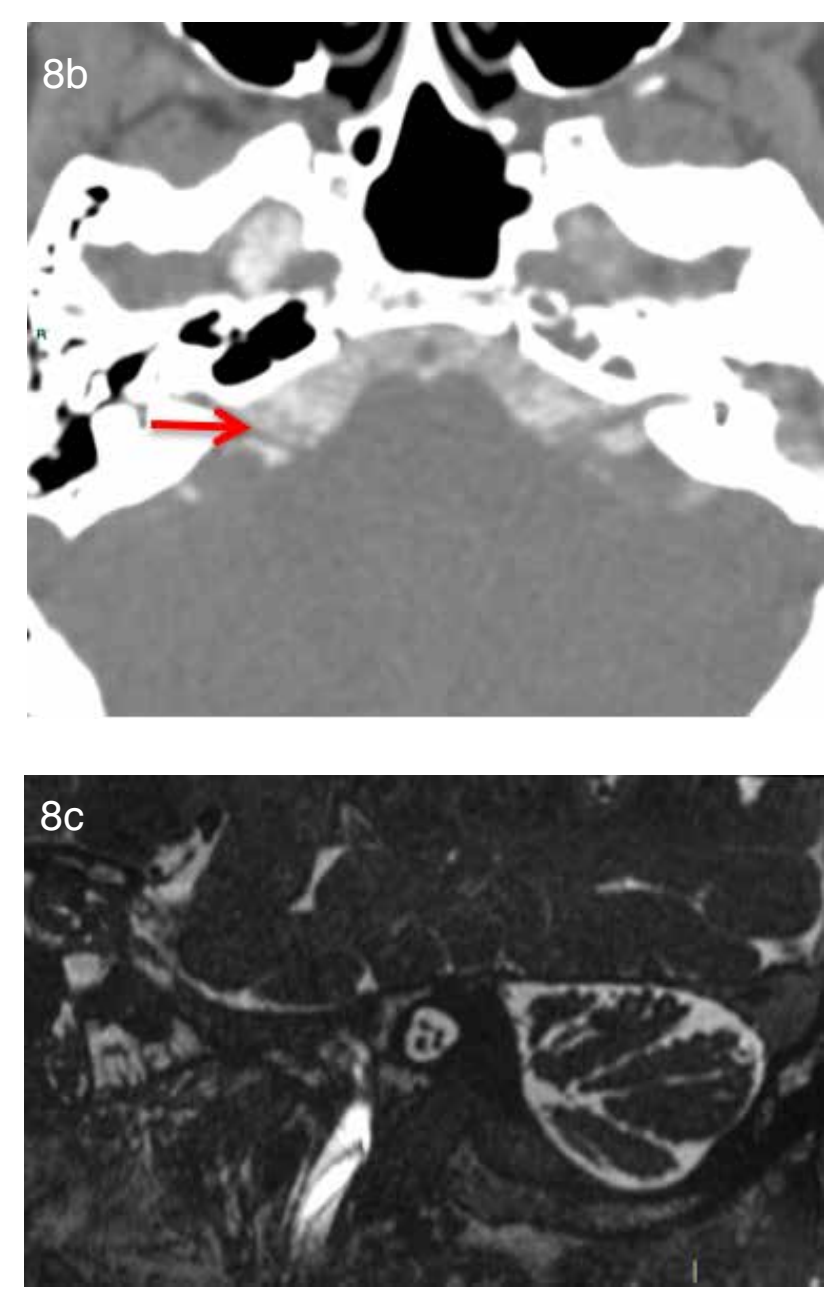

Figura 8: Corte axial en TC en ventana ósea (a) y cisternoTAC (b) del conducto auditivo interno. (b) Ingreso por el agujero auditivo interno del nervio facial (VII) y vestibulococlear (VIII). Corte sagital oblicuo (c) del CAl en secuencia FIESTA de RM, con los nervios facial (superior y anterior), coclear (inferior $y$ anterior), vestibulares superior e inferior (posteriores).

timpánica (nervio de Jacobsen) y el seno petroso inferior. La pars vascularis es más grande y de tamaño variable, y transmite la vena yugular interna, el décimo (X) nervio craneal (nervio vago) con su rama auricular (nervio de Arnold), el undécimo (XI) nervio craneal y la arteria meníngea posterior. La apariencia del foramen yugular es variable y algunas veces ambos nervios craneales IX y X atraviesan la pars nervosa. El foramen yugular derecho es más grande que el izquierdo en el 75\% de la población(6) (Figura 9).

Canal del hipogloso: El canal hipogloso se localiza entre el cóndilo occipital y el tubérculo yugular y se extiende oblicuamente hacia anterior (posteromedial a anterolateral) permitiendo que el nervio hipogloso (NC XII) emerja desde la fosa craneal posterior.

El canal hipogloso se identifica más fácilmente en imágenes axiales o coronales a través de los cóndilos occipitales, donde se puede ver transcurriendo anterior y lateral desde la fosa posterior hacia la parte superior del cuello(17) (Figura 9).

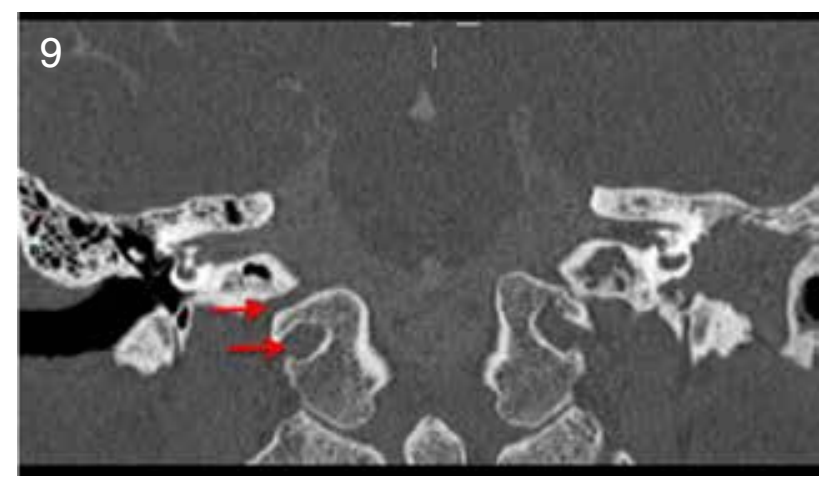

Figura 9: Corte coronal de tomografía computada en ventana ósea muestra en orden descendente el foramen yugular y el canal del hipogloso.

\section{Conclusión}

La base del cráneo forma el piso de la cavidad craneal que separa el cerebro de las estructuras faciales y el cuello suprahioideo. La anatomía de la base del cráneo es compleja y no es directamente accesible para la evaluación clínica. En la base del cráneo se pueden identificar tres regiones cuando se ve desde superior, las fosas craneales anterior, media y posterior. Se observan varios forámenes y canales en la base del cráneo, que transmiten estructuras neurovasculares relativamente constantes. La TC y la RM son la modalidad de imagen de elección para la evaluación de la anatomía y la patología de la base del cráneo y cumplen un rol complementario.

\section{Referencias}

1. Som PM, Curtin HD. USA: Elsevier Health Sciences; 2002. Head and Neck Imaging.

2. Valenzuela R, Ebensperguer E. Base de cráneo: Anatomía y patología tumoral. Revisión conceptual. Revista Chilena de Radiología. 2002; 8(4): 170-176.

3. Federle MP, Rosado-de-Christenson ML, Woodward PJ. Diagnostic and Surgical Imaging Anatomy: Chest, abdomen, pelvis. Amirsys; 2006. 1250 p.

4. Laine FJ, Nadel L, Braun IF. CT and MR imaging of the central skull base. Part 2. Pathologic spectrum. Radiographics. 1990 Sep; 10(5): 797-821.

5. Parmar H, Gujar S, Shah G, Mukherji SK. Imaging of the anterior skull base. Neuroimaging Clin N Am. 2009; 19: 427-439. [PubMed]

6. Harnsberger R, Hudgins P, Wiggins R, Davidson C. Salt Lake City, USA: AMIRSYS; 2004. Diagnostic Imaging: Head and Neck, 1e.

7. Bou-Assaly W, Srinivasan A, Mukherji SK. Head and neck high-field imaging: Oncology applications. Neuroimaging Clin N Am. 2012; 22: 285-296. [PubMed] 
8. Raut AA, Naphade PS, Chawla A, Imaging of skull base: Pictorial essay. Indian J Radiol Imaging. 2012 Oct; 22(4): 305.

9. Gray H; Warwick R, Williams PL, eds. Gray's anatomy. 35th British ed. Philadelphia: Saunders, 1973; 288-29; 695-696.

10. Sondheimer FK. Basal foramina and canals. In: Newton Th, Potts DG, eds. Radiology of the skull and brain. New York: Mosby, 1971; 287-347.

11. Meschan I. An atlas of anatomy basic to radiology. Philadelphia: Saunders, 1975; 235-241.

12. Blitz AM, Choudhri AF, Chonka ZD, Ilica AT, Macedo LL, Chhabra A, Gallia GL, Aygun N. Anatomic considerations, nomenclature, and advanced crosssectional imaging techniques for visualization of the cranial nerve segments by MR imaging. Neuroimaging
Clinics. 2014 Feb 1; 24(1): 1-5.

13. Daniels DL, Peck P, Mark L, Pojunas K, Wilhams AL, Haughton VM. Magnetic resonance imaging ofthe cavernous sinus. AJR 1985; 144: 1009-1014; 243.

14. Djindjian R, MerlandJj. Super-selective arteriography of the external carotid artery. Bertin: Springer-Verlag, 1978; 24-25.

15. Chong VF, Khoo JB, Fan YF. Imaging of the nasopharynx and skull base. Neuroimaging Clin N Am. 2004; 14: 695-719. [PubMed]

16. Coin CG, Malakasian DR. Clivus. In: Newton Th, Potts DG, eds. Radiology of the skull and brain. New York: Mosby, 197 1; 348-356.

17. Thurston M., Gaillard, F. Cranial nerves [Internet]. Radiopaedia [cited 28 May 2018]. Available from: https://radiopaedia.org/articles/cranial-nerves 